\title{
Maternal complications in twin pregnancy; recent trends: a study at a tertiary care referral institute in Northern India
}

\author{
Sunita Dubey*, Reeti Mehra, Poonam Goel, Jyotsna Rani, Mohit Satodiya
}

Department of Obstetrics and Gynecology, Government Medical College and Hospital, Chandigarh, India

Received: 08 July 2018

Accepted: 02 August 2018

*Correspondence:

Dr. Sunita Dubey,

E-mail: sunitas504@gmail.com

Copyright: (C) the author(s), publisher and licensee Medip Academy. This is an open-access article distributed under the terms of the Creative Commons Attribution Non-Commercial License, which permits unrestricted non-commercial use, distribution, and reproduction in any medium, provided the original work is properly cited.

\begin{abstract}
Background: This study aims to determine the maternal complications in twin pregnancy in North Indian population at tertiary institute.

Methods: This was a retrospective cohort review of multiple pregnancies after 20 weeks gestation at a tertiary teaching hospital (2011-2015). Maternal data was collected from the labor room delivery data entry register and patient's admission file. Patients with diabetes mellitus and chronic hypertension were excluded from the study.

Results: Out of 19539 births during this period, 432 were twin pregnancies with an incidence of 22/1000 birth. Most of them $282(65.4 \%)$ were referred patients. Eighty seven percent patients were in the age group of 21-30 years and primigravida contributed to $45.7 \%$ of total patients. Maternal complications noticed were as preterm deliveries in 304 $(70 \%)$, anaemia in $259(60 \%)$ patients, preterm rupture of membranes in $120(39.4 \%)$ patients, hypertensive disorders of pregnancy in $122(28.3 \%)$ patients, cholestasis of pregnancy in $24(5.5 \%)$ of patients, hypothyroidism in $22(5.1 \%)$ of patients, antepartum hemorrhage (APH) in 20(4.6\%) and gestational diabetes mallitus (GDM) in 08(1.8\%) of patients. Among postpartum complications, atonic postpartum haemorrhage (PPH) was observed in $44(10.2 \%)$ and maternal mortality happened in $02(0.46 \%)$ cases.

Conclusions: This study reveals higher percentage of preterm labor, anaemia and gestational hypertension than other studies. More number of intensive care unit should be established in high prevalence areas to prevent perinatal mortality due to prematurity. Treatment of anaemia requires more aggressive approach by considering intravenous iron whenever compliance is in doubt. Frequent antenatal care is required for early diagnosis of these complications to prevent maternal and fetal morbidity.
\end{abstract}

Keywords: Multiple pregnancies, Preterm labour, Preterm rupture of membranes, Preeclampsia, Twin pregnancy

\section{INTRODUCTION}

Although, incidence of multiple pregnancies is variable according to race, age and parity of patients, rising incidence of multiple pregnancy is commonly attributed to fertility enhancing treatments. ${ }^{1-4}$

Maternal and fetal complications are increased from antenatal period to postpartum period except postdatism and macrosomia in multiple pregnancies. Most grave and common complication of multiple pregnancies is preterm delivery that increases the short and long-term perinatal morbidity and mortality. ${ }^{5}$ Others fetal complications are specific to and more in monochorionic pregnancies like discordant twin, twin -twin transfusion syndrome, twin reversed arterial perfusion sequence, twin anemia polycythemia sequence, single fetal demise and congenital anomalies, thus diagnosis of chorionicity is must in early trimester. ${ }^{6}$ Undiagnosed cases of chorionicity ought to be treated like monochorionic pregnancies to avoid fetal morbidity and mortality. A significant maternal hemodynamic change due to increase 
in cardiac output and plasma volume predisposes to physiological anemia in multiple pregnancies. ${ }^{7}$ High incidence of hypertensive disorders of pregnancy have been observed in multiple pregnancies. ${ }^{8}$ Hence, increase in plasma volume, anemia and hypertensive disorders in combination increases the risk of pulmonary edema in multiple pregnancies which further increases the risk of maternal morbidity and mortality. ${ }^{9}$

Association of gestational diabetes with multiple pregnancies is still not clear. No significant association of gestational diabetes mellitus with multiple pregnancies was found in one of the study by Buhling $\mathrm{KJ}$ et al. ${ }^{10}$ Higher incidence of antepartum haemorrhage has been associated with placenta previa along with toxemic abruptio in twin pregnancy. ${ }^{11}$

Atonic postpartum haemorrhage occurs due to overdistended uterus therefore patients with multiple pregnancy have more risk of blood transfusion and its complications. ${ }^{12}$ Henceforth, specialized antenatal care is advocated in cases of multiple pregnancies to improve the maternal and fetal outcome by identifying these complications at early instance. World Health Organization has established favourable maternal and fetal outcome by early detection of complications through increasing number of antenatal contacts with health care provider. ${ }^{13}$ This study was planned to determine incidence of maternal complication in twin pregnancy in north Indian population at tertiary care hospital.

\section{METHODS}

This was a retrospective cohort review of twin pregnancies who delivered after 20 weeks gestation from December 2011 to November 2015 in the Obstetrics Department of Government medical college and Hospital (GMCH), Chandigarh, tertiary centre and teaching institute. This study was conducted after approval from research and ethical committee of GMCH, Chandigarh.

Maternal data was collected from the institution labor room delivery data entry register and detailed information was obtained by analysis of individual patient records. Patients with chronic disease like chronic hypertension and diabetes mellitus were excluded.

The following data were recorded for each case: maternal age, parity, gestational age at birth and route of delivery. Following Maternal complications were analyzed: Prevalence of preterm delivery, preterm rupture of membranes, anemia, gestational hypertension, and cholestasis of pregnancy, antepartum haemorrhage, gestational diabetes mellitus and postnatal complications including postpartum hemorrhage and maternal mortality.

Anaemia was classified by WHO criteria: mild anaemia 9-10.9gm/dl, moderate anaemia 7-8.9 gm/dl and severe anaemia $<7 \mathrm{gm} / \mathrm{dl}$.
Postpartum haemorrhage was defined when more than $500 \mathrm{ml}$ blood loss in normal delivery and 1liter in cesaearn section or any amount of blood loss that leads to unstable vitals in postpartum period.

\section{Statistical analysis}

Data was analysed using SPSS version 22. Results were expressed as frequency and percentage.

\section{RESULTS}

During this study period, a total of 432 twin pregnancies were found with a gestational age of more than 20 weeks. Out of 432 twin pregnancies, only one patient with diabetes mellitus was excluded from the study.

Table 1: Maternal complications in twin pregnancy.

\begin{tabular}{|ll|}
\hline Maternal complications & Frequency/Percentage \\
\hline Antenatal complications & \\
\hline Total Preterm delivery & $304(70 \%)$ \\
\hline $\begin{array}{l}\text { Spontaneous preterm } \\
\text { delivery }\end{array}$ & $272(89.4)$ \\
\hline $\begin{array}{l}\text { Induced preterm delivery } \\
\text { PTROM }\end{array}$ & $32(10.5 \%)$ \\
\hline Route of delivery & $120(39.4 \%)$ \\
\hline Vaginal delivery & $212(49.1 \%)$ \\
\hline LSCS & $224(51.9 \%)$ \\
\hline Anaemia & $259(60 \%)$ \\
\hline Mild & $103(39.7 \%)$ \\
\hline Moderate & $139(53.6 \%)$ \\
\hline Severe & $17(6.5 \%)$ \\
\hline $\begin{array}{l}\text { Hypertensive disorders of } \\
\text { pregnancy }\end{array}$ & $122(28.3 \%)$ \\
\hline $\begin{array}{l}\text { Cholestasis of pregnancy } \\
\text { Hypothyroidism }\end{array}$ & $24(5.5 \%)$ \\
\hline $\begin{array}{l}\text { Antepartum hemorrhage } \\
\text { (APH) }\end{array}$ & $22(5.1 \%)$ \\
\hline Toxaemic abruptio & $20(4.6 \%)$ \\
\hline Nontoxemic abruptio & $09(2.06 \%)$ \\
\hline $\begin{array}{l}\text { Placenta previa } \\
\text { Gestational diabetes } \\
\text { mellitus (GDM) }\end{array}$ & $07(1.5 \%)$ \\
\hline Pospartum complications & $08(1.8 \%)$ \\
\hline $\begin{array}{l}\text { Atonic postpartum } \\
\text { haemorrhage }\end{array}$ & $44(10.2 \%)$ \\
\hline Maternal mortality & $02(0.46 \%)$ \\
\hline
\end{tabular}

Total number of births during this period were 19539, with incidence of $22 / 1000$ birth of twin pregnancies. Assisted reproductive techniques contributed to $13.4 \%$ of twin pregnancies. Eighty six percent $(86.9 \%)$ of patients were in the age group of 21-30 years and primigravida contributed to $45.7 \%$ of total patients. The rate of cesarean section was 224/431 (51.9\%) and cesarean section for delivery of second twin was happened in 5 patients. Most common indication of cesarean section was abnormal presentation 114/224 (50.9\%) followed by 
previous cesarean section $37 / 224(16.5 \%)$, fetal distress $33 / 224(14.7 \%)$ and $40 / 224(18 \%)$ were for miscellaneous indications. Results of maternal medical complications are given in Table 1 .

\section{DISCUSSION}

The prevalence of (22/1000 birth) of twin pregnancies in this study was on higher side which is related to the fact that we are at a tertiary level teaching hospital that received referrals for complicated cases and multiple gestations from nearby health care centre. The prevalence of twin gestation in an Indian population was reported from 5/1000 to 29/1000 birth by Deepthi et al and Tomer SP et al respectively. ${ }^{14,15}$

Although it was thought that prevalence of multiple births is more in advanced age group due to more use of fertility treatment and rise in follicle stimulating hormone concentration with age. However, in this study, $86.9 \%$ of multiple gestations were found in the age group of 21-30 years. A study by Tomar SP et al also revealed $81 \%$ of multiple births in the age group of 20-29 years. ${ }^{15}$ The high prevalance of multiple pregnancies in young age may be due to early age of marriage and childbirth in the study population.

Primigravida were $45.7 \%$ and multigravia contributed to $54.3 \%$ of twin gestations. Chowdhury $\mathrm{S}$ et al reported more number of preterm deliveries in multigravida as compared to primigravida patients. While $\mathrm{N}$ Rezavand observed no difference in parity among multiple pregnancies. $^{16}$

Only $13.4 \%$ of twin conceptions were contributed by assisted reproductive techniques and explained by the profile of patients at our institute where services are mostly availed by the patients belonging to low socioeconomic stratum.

Deepthi et al and Nandmer $\mathrm{G}$ et al reported preterm delivery in $60 \%$ and $67 \%$ of twin pregnancies respectively. ${ }^{14,17}$ Whereas, Shetty $\mathrm{MB}$ et al and Chowdhury et al reported much lower incidence of preterm delivery in $38 \%$ and $44 \%$ of patients respectively. ${ }^{18,19}$

The inherited risk of preterm delivery in multiple pregnancies is supported by higher incidence of preterm delivery in this study, out of 304 (70\%) preterm delivery $272(89.4 \%$ had spontaneous preterm labor and 32 $(10.5 \%)$ were induced preterm delivery. Preterm rupture of membranes was observed in $120(39.4 \%)$ of patient in this study. Whereas Shetty MB et al and chaudhary et al reported much lower incidence of preterm rupture of membranes in $6.09 \%$ and $3.8 \%$ of patients respectively. ${ }^{18,19}$

Multiple pregnancies are amongst the main causes of rising incidence of primi cesarean section due to abnormal presentation of first twin. The rate of cesarean section in present study was 224/431 (51.9\%) and supported by Shetty MB et al, Chowdhury et al and Deepthi et al who have reported cesarean section in $68 \%$, $49 \%$ and $45 \%$ of twin pregnancies respectively. ${ }^{14,18,19} \mathrm{~A}$ study by Assuncao et al has reported cesarean section in $84.8 \%$ of patients that is explained by higher incidence of $(42.8 \%)$ iatrogenic preterm delivery in that study. ${ }^{20}$

Inspite of many efforts to prevent anemia under various programmes, it is still prevalent in adolescent and pregnant women. This study also revealed anaemia as most common medical complications $(60 \%)$ in contrast to other studies where it was reported in $16.6 \%-35.8 \%$ of multiple pregnancies. ${ }^{14,19}$ This high prevalence of anaemia in this study may be due to more number of referred patients who had taken inadequate treatment in antenatal period. Second commonest maternal complication in this study was hypertensive disorders of pregnancy with an incidence of 122/431 (28\%), Deepti et al, Sheela SR et al and Chowdhury $\mathrm{S}$ et al reported hypertensive disorders of pregnancy in $11.66 \%, 14.5 \%$, $22.6 \%$ of multiple pregnancies respectively. ${ }^{14,19,20}$ Antepartum haemorrhage was noticed in $20(4.6 \%)$ of patients similar to that reported by Chowdhury $\mathrm{S}$ et al in $3(5.7 \%)$ of patients whereas Shetty MB et al reported much higher incidence of ante-partum haemorrhage in twin gestations $(32.2 \%) .{ }^{19,18}$

Cholestasis of pregnancy was observed in 24 (5.5\%) patient in this study and its rate was lower than reported by Gonzalez MC et al $(20.9 \%){ }^{22}$ GDM was occurred in $1.8 \%$ of patients in this study whereas Chowdhury S et al have reported GDM in $5.7 \%$ of patients. ${ }^{19}$ Buhling KJ et al reported GDM in $3.4 \%$ of patients and did not found any association with twin pregnancy. ${ }^{10}$ Atonic postpartum haemorrhage (PPH) was occurred in 44(10.2\%) of patients that was lesser than reported $(18.9 \%)$ by Chowdhury et al that may be due to prophylactic use of misoprostol in addition to oxytocin after delivery in our institute in all multiple births. ${ }^{19}$

Maternal mortality happened in $2(0.46 \%)$ cases in referred patients, one was due to atonic postpartum hemorrhage who presented with eclampsia and with pulmonary edema and other had severe anemia $(3.8 \mathrm{gm} / \mathrm{dl})$ with pulmonary edema in shock. The prevalence of maternal death was higher in twin mothers compared to singleton mothers $(0.3 \%$ vs $0.1 \%, \mathrm{p}, 0.009)$, in a study by Vogel JP et al. ${ }^{23}$

From the result of this study, it can be emphasized that twin pregnancies are at higher risk of preterm delivery that needs referral to higher centre for better neonatal care. There is a need to establish multiple pregnancies clinic in high prevalence areas to detect multiple pregnancy related complications so that early intervention may prevent morbidity and mortality both for the mother and fetus. The positive point of this study is largest study population size as compared to other studies. The major 
negative aspect of this study is being a retrospective observational study.

\section{CONCLUSION}

This study revealed higher percentage preterm labour, anemia, gestational hypertension in twin pregnancy as compared to other studies. Anaemia, hypertensive disorder of pregnancy along with postpartum haemorrhage are the well-known causes of maternal mortality, thus frequent antenatal visits should be aimed to detects maternal complications earlier. Aggressive treatment of anemia with intravenous iron should be considered whenever there are adverse effects or noncompliance to oral iron. Atonic postpartum haemorrhage should be anticipated in all multiple pregnancies, therefore prophylactic treatment should be prearranged for its prevention.

Funding: No funding sources

Conflict of interest: None declared

Ethical approval: The study was approved by the Institutional Ethics Committee

\section{REFERENCES}

1. Practice committee of american society for reproductive medicine. Multiple gestation associated with infertility therapy: an American Society for Reproductive Medicine Practice Committee opinion. Fertil Steril 2012; 97:825.

2. Lisonkova S, Joseph KS, Bell R, Glinianaia SV. Effect of advanced maternal age on perinatal outcomes in twins: the impact of chorionicity. Ann Epidemiol. 2013 Jul 1;23(7):428-34.

3. Nkyekyer K. Multiple pregnancy. In: Kwawukume EY, Emuveyan EE, editors. Comprehensive Obstetrics in the Tropics. $1^{\text {st }}$ ed. Asante and Hittscher Printing Press Limited; 2002. p. 162-72.

4. Adashi EY. Seeing double: a nation of twins from sea to shining sea. Obstetr Anesthesia Digest. 2017 Mar 1;37(1):16.

5. Hamilton BE, Martin JA, Osterman MJ, Curtin SC, Matthews TJ. Births: Final data for 2014. Natl Vital Stat Rep. 2015;64(2):1-64.

6. Hack KE, Derks JB, Elias SG, Franx A, Roos EJ, Voerman SK, et al. Increased perinatal mortality and morbidity in monochorionic versus dichorionic twin pregnancies: clinical implications of a large Dutch cohort study. BJOG: Int J Obstetr Gynaecol. 2008 Jan 1;115(1):58-67.

7. Kametas NA, McAuliffe F, Krampl E, Chambers J, Nicolaides KH. Maternal cardiac function in twin pregnancy. Obstetr Gynecol. 2003 Oct 1;102(4):80615.

8. Sibai BM, Hauth J, Caritis S, Lindheimer MD, MacPherson C, Klebanoff M, et al. Hypertensive disorders in twin versus singleton gestations. Am J Obstetr Gynecol. 2000 Apr 1;182(4):938-42.
9. Rao A, Sairam S, Shehata H. Obstetric complications of twin pregnancies. Best Prac Res Clin Obstet Gynaecol. 2004 Aug 1;18(4):557-76.

10. Buhling KJ, Henrich W, Starr E, Lubke M, Bertram S, Siebert G, Dudenhausen JW. Risk for gestational diabetes and hypertension for women with twin pregnancy compared to singleton pregnancy. Arch of Gynecol Obstetr. 2003 Nov 1;269(1):33-6.

11. Ananth CV, Demissie K, Smulian JC, Vintzileos AM. Placenta previa in singleton and twin births in the United States, 1989 through 1998: a comparison of risk factor profiles and associated conditions. Am J Obstetr Gynecol. 2003 Jan 1;188(1):275-81.

12. Santana DS, Cecatti JG, Surita FG, Silveira C, Costa ML, Souza JP, et al. Twin pregnancy and severe maternal outcomes: the World Health Organization multicountry survey on maternal and newborn health. Obstetr Gynecol. 2016 Apr 1;127(4):631-41.

13. Implementation of the ANC guideline and recommendations. WHO recommendations on antenatal care for a positive pregnancy experience. 2016;4:105-7.

14. Deepthi HR, Pradeep MR, Lalitha S. Retrospective study of maternal and perinatal outcome of twin pregnancy in a teaching hospital. J Dental Med Sci. 2015;14(1): 29-32.

15. Tomar SP, Kushwah SS, Kushwah AP. Association of sociodemographic factors with multiple births and birth outcomes in comparison to single births among deliveries conducted at a tertiary hospital in Rewa, Madhya Pradesh. Int J Students' Res. 2014 Jan $1 ; 4(1): 8$.

16. Rezavand N, Veisi F, Malek-Khosravi S, Zangeneh M, Kohzadi M. Assessment of Frequency of Twin Pregnancy and Neonatal Outcome in Deliveries of Mo'tazedi Hospital, Kermanshah in 2004-2007. J Obstetr Gynecol India. 2014 Feb 1;64(1):19-22.

17. Nandmer GK, Kanhere AV. Study of obstetric and fetal outcome of twin pregnancy in a tertiary care centre. Int J Reprod Contracept Obstetr Gynecol. 2017 Feb 19;4(6):1789-92.

18. Shetty MB, Shivananjaiah C, Swarup A. A retrospective study: twin gestation at tertiary care, maternal and fetal outcome. Int J Reprod Contracept Obstetr Gynecol. 2016 Dec 16;5(1):217-9.

19. Chowdhury S, Hussain MA. Maternal complications in twin pregnancies. Mymensingh Med J. 2011 Jan;20(1):83-7.

20. Sheela SR, Patila A. A study of maternal and fetal outcome in multifetal gestation at a rural based teaching hospital-a retrospective analysis. Int J Biol Med Res. 2014;5(2):3994-7.

21. Assunção RA, Liao AW, Brizot MD, Krebs VL, Zugaib M. Perinatal outcome of twin pregnancies delivered in a teaching hospital. J Brazilian Med Ass. 2010;56(4):447-51.

22. Gonzalez MC, Reyes H, Arrese M, Figueroa D, Lorca B, Andresen M, et al. Intrahepatic cholestasis of pregnancy in twin pregnancies. J Hepatol. 1989 Jul;9(1):84-90. 
23. Vogel JP, Torloni MR, Seuc A, Betrán AP, Widmer M, Souza JP, et al. Maternal and perinatal outcomes of twin pregnancy in 23 low-and middle-income countries. PloS one. 2013 Aug 1;8(8):e70549.
Cite this article as: Dubey S, Mehra R, Goel P, Rani J, Satodiya M. Maternal complications in twin pregnancy; recent trends: a study at a tertiary care referral institute in Northern India. Int J Reprod Contracept Obstet Gynecol 2018;7:3753-7. 